\title{
La moral y las noticias
}

\author{
Robert EZRA PARK ${ }^{1}$ \\ Traducción de Eva Aladro Vico
}

\begin{abstract}
(Abstracts y palabras clave al final del artículo)
Propuesto: 7 de diciembre de 2012

Evaluado: 18 de diciembre de 2012

Aceptado: 22 de diciembre de de 2012
\end{abstract}

\section{PROPAGANDA}

Desde que la guerra ha invadido el mundo del espíritu, la moral ha cobrado una importancia nueva, tanto en la contienda como en la paz. Una guerra global es hoy una empresa tan colosal, que las naciones beligerantes hallan necesario no sólo movilizar todos sus recursos, materiales y morales, sino que convierten la pequeña paz actual en una simple preparación para la guerra futura. En estas condiciones la llamada guerra psicológica, que se está desarrollando entre los estados en actual contienda bélica, ha asumido una importancia, y conseguido tal eficacia técnica, que si no ha cambiado la naturaleza misma de la guerra, sí ha alterado profundamente el carácter de la paz, haciéndola mucho más dura de sostener.

El objeto de ataque en la guerra psíquica es la moral, y menos la de los hombres movilizados en combate, que la de la población civil en la retaguardia. Pues la "estrategia del terror" se dirige más bien a los no combatientes y contra quienes deben esperar aguantando la situación, que contra los que pueden de algún modo devolver el golpe ${ }^{2}$. Curiosamente, éste es un modo en el cual la guerra total, en tanto es una guerra de nervios, fracasa en sus objetivos finales. Y fracasa porque le da a todo el mundo algo que hacer; también porque, dado que implica la participación,

\footnotetext{
1 Texto publicado originariamente en 1941 por el American Journal of Sociology, reditado en 1955 en el libro Society, por The Free Press Glencoe, 1955, pp. 126-143.

Park muestra su profundidad de pensamiento, capaz de pasar la barrera de los 80 años, y de traernos la actualidad de sus ideas en una época casualmente paralela. Muy interesante su penetración de la acción social en tiempos de crisis: es necesario que en una crisis se actúe como una nación, y se esté unido como pueblo, afirma. Es una delicia comprobar su honda cultura y leer su cita de Ortega y Gasset. Capaz de aglutinar interdisciplinarmente conocimientos de la psicología social, filosofía, antropología, teoría del periodismo, o política, con toda libertad indicó el camino a seguir. La mejor definición de noticia, probablemente está en este texto. La gran paradoja fue que a pesar de ser periodista concibió una teoría genial de la noticia, basándose en una inspiración social increíble. Agradecemos a Emilio Martín Martínez, su traductor en España y profesor de la UCM, su indicación de este texto para su traducción en CIC.
}

2 Taylor, Edmund, Strategy of Terror (Boston, Houghton Mufflin Co., 1940). 
aunque sólo sea simbólica, en una gran empresa colectiva, es a la vez una fuente de inspiración y de consuelo. Por ello, tiende finalmente a hacer crecer la solidaridad y a mejorar la moral, no solamente de la población civil, sino del ejército también. Así parece haber ocurrido absolutamente en Inglaterra, donde, según se ve, se ha creado un espíritu nacional y una solidaridad que no existía desde la época de la guerra contra la Armada española.

El deseo de unirse a los demás en una acción colectiva es uno de los móviles más elementales que activan a la raza humana. La conciencia y la emoción de participar en grandes acontecimientos constituye una de las experiencias humanas más satisfactorias y estimulantes. En la reverberación que esa participación invariablemente crea en las mentes de los otros, la acción de cada individuo que participa adquiere una dignidad nueva y una nueva gloria, así como recibe ella misma un apoyo moral añadido.

Es en y a través de estas grandes empresas colectivas - guerras, revoluciones, o movimientos sociales, como el movimiento de los trabajadores- como aparecen las nuevas instituciones y las viejas se ven a veces rejuvenecidas. Nadie parece haber entendido eso mejor que José Ortega y Gasset, el autor de La España invertebrada. En el momento en que se publica este libro en 1937, nadie tenía más motivos para comprender, pues estos ensayos analizan los procesos atravesados por España en el integrarse y desintegrarse del imperio español y de la unidad nacional española. Lo que el autor afirma de España es especialmente pertinente hoy respecto al resto del mundo y al tema de nuestro artículo. El primero de sus ensayos se titula "Cómo hacer y cómo romper una nación".

"No es el ayer, la tradición, el pasado", afirma, "lo decisivo, la fuerza determinante en una nación. Las naciones se hacen y siguen viviendo porque tienen un programa para el futuro". No es ni importante ni necesario para la unidad, para la solidaridad, añade, "que las partes que componen una sociedad coincidan en sus ideas y en sus deseos; lo importante, la cuestión esencial, es que cada una conozca y hasta cierto punto incorpore a su propia vida las ideas y los deseos de los demás". ${ }^{3}$

No hay probablemente otro proceso social, ni otra forma de interacción, en la que los componentes individuales de una sociedad se vean más completa y efectivamente integrados, si no fusionados, que con la participación en alguna forma de acción colectiva. De hecho, tal y como algunos escritores han sabido ver, la sociedad existe y "se hace a la mar", por usar un término naútico, solamente cuando es capaz de la acción consensuada y consistente.

Los grupos que se llaman "nosotros" son típicamente los grupos que actúan. Particularmente es cierto esto si incluimos en este término toda forma de sociedad en la que el etnocentrismo o la auto-conciencia del grupo se manifiesta habitualmente. Es cierto que una masa o una multitud no piensa en sí misma como en "nosotros"; a menos que entre en contacto y en conflicto con alguna otra masa o multitud. En este caso es corriente que ese grupo asuma el carácter de una banda, se otorgue a sí mismo un nombre y quizás asuma vagamente un sentido de posesión exclu-

3 José Ortega y Gasset, La España invertebrada. La edición que cita Park es de Nueva York, Norton, 1937, pp. 19-45. 
siva de un territorio con su hábitat particular. Esta conducta es característica de algunos animales inferiores -los pájaros en particular. Si me aventuro a mencionar este tipo básico de sociedad a este respecto, es para resaltar el hecho de que no solamente los ejércitos y las naciones necesitan algún tipo de moral, sino que todo tipo de agrupación social debe actuar efectivamente para sobrevivir en un conflicto con otras asociaciones.

Las artes y los dispositivos mediante los cuales puede elevarse la moral de un pueblo o revivir, incluso crear directamente, su espíritu nacional, así como los métodos por los que la solidaridad nacional de un pueblo enemigo puede minarse y finalmente destruirse, se han mostrado convincentemente en la historia reciente de Europa, y las noticias más recientes los ilustran con abundancia. En los reportajes en primera persona de observadores y participantes del presente conflicto europeo, hallamos material para una ciencia política más realista, como la que se atribuye históricamente a Machiavello pero que se halla más reciente y sistemáticamente ejemplificada en los textos del sociólogo italiano Pareto. Para esa ciencia política realista, los relatos de primera mano de esos acontecimientos políticos, como los de William Shirer en su Diario de Berlin son algo así como un manual. Su relato de una de las primeras "reuniones de animación" del partido nazi en Nuremberg es una contribución no ya para la Historia, sino para la Sociología. "Reuniones de animación" no es el vocablo adecuado para las ceremonias de Nuremberg. Una palabra menos secular y más sugerente de una revivificación religiosa lo describiría mejor. Éste es un extracto del diario del 5 de septiembre de 1934 en Nuremberg:

"Empiezo a comprender, creo, algunas de las razones del éxito asombroso de Hitler. Ha tomado prestado un capítulo de la Iglesia Romana, y está restableciendo el boato, el color y el misticismo en las oscuras vidas de los alemanes del siglo veinte. El meeting de inauguración de esta mañana en el Hall Luitpold, a las afueras de Nuremberg, ha sido algo más que un show espectacular; tiene algo del misticismo y del fervor religioso de una misa de Pascua o de Navidad en una gran catedral gótica. El lugar era un mar de banderas de color. Incluso la llegada de Hitler ha resultado dramática. La banda dejó de tocar. Entre las treinta mil personas presentes, apelotonadas en el hall, se produjo un rumor. En ese instante la banda comenzó a tocar con mucho brio la Marcha Badenweiler, una música muy pegadiza, que solamente usan, según me cuentan, cuando Hitler hace sus grandes entradas. Hitler apareció en la parte de atrás del auditorio, seguido por sus asistentes Göring, Goebbels, Hess, Himmler, y los demás, caminando despacio por el largo pasillo central mientras treinta mil manos se levantaban haciendo el saludo nazi. Se trata de un ritual, dicen los más veteranos, que se sigue siempre igual. Después una orquesta sinfónica inmensa empieza a tocar la Obertura Egmont de Beethoven. Grandes focos de cañón se encienden en el escenario mientras Hitler se sienta rodeado de un centenar de oficiales del partido y del ejército de tierra y la marina. Tras el, la "bandera de sangre", la que llevaban por las calles de Munich en la fatídica noche de los cristales rotos. Y detrás de todo eso, quinientos o seiscientos oficiales de las S.A.. Cuando termina la música, Rudolf Hess, el confidente más próximo a Hitler, se levantó y leyó lentamente los nombres de los "mártires "nazis -camisas negras muertos en la lucha por el poder - pasando lista a los fallecidos, lo que conmovió mucho a los treinta mil asistentes. 
En esta atmósfera no es nada extraño que cada palabra emitida por Hitler pareciera un Verbo inspirado desde lo alto. La facultad crítica humana - $\mathrm{o}$ al menos la alemana- es barrida en esos momentos, y cada mentira que se dice se acepta como una enorme verdad esencial."

Las artes y los dispositivos de ataque espiritual son muchos y variados, y más sutiles sin duda de lo que cualquier análisis nos haya mostrado hasta ahora. Pero una de las armas de esta munición psicológica, tanto para la ofensiva como para la defensa, es la propaganda 4 . Harold Lasswell, que ha estudiado la propaganda en una extensa investigación, y que escribe con más agudeza sobre este tema que la mayoría de los otros tratadistas a los que he consultado, ha distinguido entre educación y propaganda. Su distinción se basa en la diferencia entre dos elementos o dos aspectos de la cultura que él describe como "técnica" y "valor". Afirma: "La inculcación de los valores y actitudes tradicionales es lo que normalmente se llama educación, mientras que el término propaganda se reserva para la difusión de actitudes subversivas, discutibles o simplemente nuevas". 5

La distinción es sustancialmente la que existe entre las noticias propiamente dichas y la propaganda, o, incluso mejor, entre las noticias y editorial. La página editorial parece inculcar no solamente actitudes sino opiniones; y las opiniones editoriales pueden ser igualmente "subversivas, discutibles o simplemente novedosas", y para la mayoría de los lectores de periódicos estadounidenses no son ni lo uno ni lo otro, dado que no las leen.

La diferencia entre noticias y editoriales es cosa conocida para un periodista, sobre todo cuando tiene la necesidad de distinguirlas, incluso aunque no siempre sea capaz de formular una definición que aclare esa diferencia en todos los casos. La esencia, o la cualidad intrínseca, de las noticias, es difícil de conocer, pero sin duda las noticias no son propaganda, y no son editoriales. En manera general podemos decir que las noticias afirman los hechos, y las editoriales, la verdad. Los hechos nos piden reflexión, deliberación, y a veces exigen que conozcamos más hechos a su vez. La verdad, sin embargo, tiene un carácter final. Cuando la tenemos, es decir, cuando estamos en posesión de la verdad completa, dejamos de investigar, de reflexionar, y nos quedamos silenciosos como una planta o empezamos a actuar como seres humanos. La propaganda suele ser más imperativa que el editorial habitual. Dado que busca la acción, se orienta a dispersar la duda y a veces finge que contiene la finalidad de la verdad, aunque su base sea una media verdad o una mentira directa.

Las noticias pueden ser y a veces lo son, el mejor tipo de propaganda, cuando sirven al propósito de un propagandista, pero las noticias y los hechos siempre admiten más de una interpretación, y este rasgo resulta fatal -la reflexión siempre resulta fatal- para la propaganda.

\footnotetext{
4 Ver Kimball Young y R.D. Lawrence, Bibliography on Censorship and Propaganda (University of Oregon Journalism Series, No 1 (Eugene, Ore.: University of Oregon, 1928).

5 Lasswell, Harold, "Propaganda", Enciclopaedia of the Social Sciences, XII (New York, 1934), 522.
} 
Los acontecimientos admiten más de una interpretación, y por eso los discutimos. De esas discusiones y diálogos emerge la opinión pública. Las discusiones no solamente crean la opinión pública, sino a veces pueden generar guerras. Sin embargo, como puede observarse, rara vez generan la paz. Parece que ésa no es su función. Cuando la discusión se desarrolla de modo ordenado y académico, como Sócrates hizo por primera vez, y como los filósofos siguen haciendo desde entonces, se denomina dialéctica. La función de la dialéctica, si puede contemplarse como un proceso social, parece ser la de testar la opinión. Ponemos a prueba la opinión averiguando si es consistente en sus diferentes expresiones. El resultado de la discusión es habitualmente el de sacar a la luz las hipótesis implícitas, e incluso los complejos implícitos, en los que se basan las opiniones divergentes. Esto conduce a veces a un acuerdo, pero a veces revela diferencias tan profundas y tan cargadas con emociones y sentimientos que la discusión posterior parece inútil, si no imposible. Cuando esto ocurre a las personas no se les presenta otro modo de continuar la controversia más que con la pelea. Cuando esto ocurre entre naciones, como ha pasado recientemente en el caso de Inglaterra y de Alemania, conduce a la guerra.

Desde este punto de vista la guerra, ya sea física o psicológica, se presenta como una instancia del proceso dialéctico. Cuando una discusión deja de ser académica, cuando toma finalmente la forma de un conflicto armado, no cesa, por usar el lenguaje de un escritor reciente, de ser "una batalla de las mentes en la que las ideas, la ideología , la propaganda y las emociones chocan en hileras ordenadas, disciplinadas como soldados" 6 . En esta batalla de mentes y de voluntades, en la que el propósito de cada parte es mantener, y si es posible mejorar, su propia moral y al mismo tiempo minar y debilitar la del enemigo, la propaganda, tanto si busca simplemente interpretar los sucesos o adoctrinar y defender las asunciones y la ideología de acuerdo con la cual se interpretan los hechos, es el arma principal de ofensiva y de defensa.

\section{MORAL}

Parece que hay cierta incertidumbre en cuanto a lo que es exactamente la moral y dónde se localiza. ¿Es algo propio del individuo o del grupo, o de ambos? Nadie duda de su importancia tanto si se localiza en el grupo o en el individuo. Es muy importante en las batallas, pero ¿cuánto?. Nadie lo sabe con precisión. Es uno de esos imponderables que todos debemos tener en cuenta pero que nadie puede medir con exactitud.

La moral, en un ejército, es "la voluntad de luchar"; en la población civil es la capacidad de soportar las duras condiciones y las malas noticias que llegan del frente. Esta voluntad de luchar y de resistir parece componerse de otros elementos: el coraje, la confianza, y virtudes cristianas como la fe, la esperanza y la caridad, si entendemos por "caridad" la comprensión -el tipo de comprensión que podemos

${ }^{6}$ Taylor, op. cit., p. 1 
encontrar en las pequeñas unidades de combate o en una familia bien organizada. La comprensión mutua es la base del esprit de corps. La caridad que claramente comienza en casa no incluye al enemigo, y la caridad en abstracto no es una cualidad de un hombre en combate.

La moral, aunque es dependiente de las cualidades que llamamos virtudes, no se identifica con las reglas o con las costumbres. Las reglas morales son hábitos y, como la consciencia, se arraigan en la tradición. Cuando se enfrentan a condiciones nuevas es muy posible que se vean confundidas e implicadas en el conflicto, el compromiso o en una dispersión de casos. Así ocurre con el objetor de conciencia. Por su parte la moral es prospectiva; radica de una manera absoluta en la disciplina y solidaridad, pero su dirección es siempre hacia el futuro. Supone la voluntad, la tendencia del organismo a actuar, organizadas en torno a una fe en el futuro y no en el interés o en una preocupación piadosa del pasado. La moral, ya sea en la paz como en la guerra, es la voluntad: la voluntad de actuar y de perseverar en un curso de acción hasta que las esperanzas que la inspiran se realicen. Mientras normalmente limitamos el término "moral" a la acción, también lo aplicamos a situaciones en las que la actividad es de rutina y no parece estar controlada o dirigida.

Cuando el presidente Roosevelt se dirigió al pueblo americano el 12 de marzo de 1933, la mayoría de los bancos de los Estados Unidos habían tenido que cerrar, y la mayoría de los estadounidenses estaban en un estado de pánico. En el curso de su alocución, afirmó: "Después de todo, hay un elemento para el reajuste en nuestro sistema financiero más importante que la liquidez, más importante que el oro, y es la confianza de las personas". El efecto de este discurso fue considerado mágico por todos. Bronislaw Malinovski, cuyos estudios sobre las islas trobriandesas le han valido la autoridad en el tema de la magia, afirmó que el discurso del Presidente fue magia. Los efectos producidos por las palabras y símbolos, si le comprendo bien, son la esencia de la magia ${ }^{7}$. Una de las funciones del mago en la sociedad primitiva, afirma el autor, es restituir la moral cuando el miedo ante un suceso no previsto y sin precedentes la golpea, como ocurrió en la reciente invasión de Marte tal como la representó Orson Welles. ${ }^{8}$

De nuevo esto nos demuestra algo que ya se ha probado anteriormente, que las palabras y los símbolos que crean y sostienen la moral de un ejército son igualmente necesarios para mantener la moral de una sociedad civil. Parece, por tanto, que debemos reconocer la moral como un factor presente en todas nuestras empresas colectivas. Es un factor que existe en las operaciones en bolsa, tanto como en las actividades del partido comunista.

Es interesante notar que en la misma fecha en que el presidente Roosevelt hizo su histórico discurso radiofónico al pueblo norteamericano, la prensa anunciaba el triunfo del partido nazi, o mejor deberíamos decir de la secta nazi, en las elecciones en Prusia. Comentando estas elecciones, el corresponsal del New York Times afirmaba: "Con esta histórica elección de los nacional-socialistas y nacionalistas, Alemania se unifica por primera vez desde los días del Antiguo Imperio". Sin

7 Malinovsky, B., Argonauts of the Western Pacific (Londres 1932)

8 Vid. Cantril, Hadley The invasion from Mars (Princeton, New Jersey University Press, 1940). 
embargo en el curso de la campaña electoral murieron doscientas personas, pero el corresponsal de Nueva York creyó que en aquel momento "la violencia se había extinguido". 9

La moral no solamente tiene un aspecto espiritual, sino físico, más específicamente, físiológico. Desde el punto de vista de la fisiología, y quizá de la sociología, la moral parece ser la capacidad de una persona o una sociedad para mantener la tensión durante un período de tiempo; para desarrollar una acción o una empresa hasta su consumación. La acción, con interrupciones, puede continuar, parece, indefinidamente, como es el caso cuando alguien actúa consistentemente para terminar una carrera o para desarrollar un proyecto al que dedica toda su vida. Lo que la tensión implica, en su fase más elemental, puede contemplarse observando cómo un gato caza a un ratón o como cualquier animal cazador acecha a su presa.

En el principio de nuestro siglo la investigación y especulación sociológicas recibieron una nueva orientación en la obra de dos autores: Scipio Sighele en Italia y Gustave Le Bon en Francia. Le Bon, cuyo tratado sobre La multitud (La Foule) ha popularizado muchísimo el nuevo punto de vista, descubrió que, bajo ciertas condiciones específicas, una agrupación casual de individuos, congregados sin ningún propósito común y aparentemente sin intereses compartidos, pueden, si se presentan las condiciones necesarias, responder a la denominada "unidad mental de las multitudes" repentinamente, y transformarse de un modo milagroso en "un solo ser único" dejando de ser una aglomeración de individualidades.

Todo esto, tal como el autor lo describe, suena asombroso. Lo que explica, sin embargo, es una experiencia familiar. Es el hecho de que una multitud, cuando se encuentra conmocionada, se convierte en un grupo organizado y resulta un agente eficaz para llevar a cabo formas muy elementales de acción colectiva, cosa que una mera aglomeración no podría hacer -por ejemplo, un linchamiento. Podemos observar el mismo fenómeno en un rebaño de ovejas o de otro tipo de ganado. Mary Austin, en su pequeño volumen titulado El rebaño, describe el modo en el que, bajo la influencia de alguna amenaza o terror repentino, un rebaño de ovejas pueden arremolinarse en un pequeño círculo cada vez más apretadas entre ellas, hasta "perecer por ahogamiento" 10

Lo que ocurre en esa situación es lo mismo que ocurre en una multitud cuando la atención de cada individuo se concentra, casualmente, en un objeto o incidente más impactante de lo habitual. Por un proceso psicológico, no muy diferente al arremolinarse del rebaño de ovejas, el interés y la excitación de cada persona se ven intensificados por la respuesta que cada individuo inconscientemente da al manifiesto interés de los demás. La multitud asume en esas circunstancias el carácter de un circuito cerrado, en el que cada individuo responde a su propia excitación nerviosa cuando la ve reflejada en las actitudes y emociones de su prójimo. El efecto de esta reacción circular es el de producir un refuerzo constante del estímulo original, así como un incremento correspondiente de la sugestionabilidad, la emoción, y la

\footnotetext{
9 Birchell, F.T., New York Times, 12 de marzo de 1933.

10 Austin, Mary, The Flock, citado en Park y Burgess, Introduction to the Science of Sociology ("a ed., Chicago, University of Chicago Press, 1924), pp. 881-82.
} 
tensión en cada individuo hasta que la masa se convierte en una unidad colectiva, psicológicamente integrada y completamente movilizada para la acción que sea que se desee o que por azar se haya planteado. En cualquier caso la acción consecuente, si tiene finalmente lugar, será repentina, impetuosa, y a menos que esté manipulada por alguien externo, será no premeditada y no planificada.

Dado que las acciones son no premeditadas ni planeadas, y se llevan a cabo sin perspectiva, no podríamos decir en el sentido habitual que la multitud tiene en estos casos una determinada moral. Cuando sin embargo una acción proyectada y planificada, requiere no solamente la disposición para actuar, sino también la voluntad para actuar consistentemente en medio de todos los accidentes, incidentes y cambios de la fortuna en un proceso largo, la moral adquiere el significado que le damos cuando hablamos, como hacemos con frecuencia hoy en día, de moral en el ejército o moral en la población civil. De todos modos, en el sentido extenso en que se usa este término a veces, como cuando nos referimos al estado de ánimo dominante en Francia antes y durante la invasión alemana, podemos, parece, hablar de la moral en cualquier sociedad o grupo en el que algún tipo de acuerdo se mantiene mediante algún tipo de comunicación. En este tipo de sociedad habrá cambios en la tensión, correspondientes con los cambios en las condiciones de vida; cambios en la orientación en respuesta a los sucesos que ocurran. En la sociedad humana siempre existen modas. Conforme las modas llegan o se pasan, las tensiones sociales se producen o ceden, y la sociedad, que inevitablemente se vuelve en la dirección de la que surjen las noticias, altera sus actitudes ante el mundo en respuesta a esos cambios que la prensa refleja.

Una de las formas más omnipresentes en las que se manifiestan la tensión y la voluntad en individuos y sociedades en mediante las emociones. Cada ocasión humana, sea un funeral o una boda, tiene su atmósfera característica. Cada reunión, incluso si no es más que una aglomeración en la calle, se ve dominada por cierto sentimiento. Uno puede notar más claramente ese estado de ánimo, quizás, cuando no puede compartirlo. En ese caso, ya sea una ocasión feliz o triste, se siente uno repelido e inevitablemente busca una compañía más acorde con uno mismo.

Me impresionó enormemente, al leer el Diario de Berlín de William Shirer, el hecho de que al parecer él notaba cada cambio que se iba dando en el clima espiritual, en un mundo que para él cada día iba resultando progresivamente menos afín. Esta atmósfera moral parece ser un indicador muy fiel, así como una condición, del estado de la moral en una comunidad civil -incluso en una comunidad pequeña como la del círculo diplomático en un país extranjero. Indiscutiblemente, era una preocupación constante de Hitler y su oficina de propaganda, preservar en Alemania una atmósfera en la población civil que apoyara la moral del ejército en el frente y el programa del gobierno en el país. Esto es lo que da relevancia a las ceremonias de Nuremberg que describe Shirer. Se trata obviamente del objetivo de toda ceremonia y de todo ritual asociado con el movimiento nazi, crear una atmósfera, una tensión, y una expectativa que, al enfocar la atención hacia las cosas que se esperan, efectivamente inhiba cualquier consideración sobre lo que contradice dichas esperanzas.

Para mantener dicha atmósfera y para proteger a la población alemana del "veneno", como Goebbels lo llamaba, de la propaganda extranjera, se desarrolló la 
censura. Para interpretar y mediar el efecto de esos reportajes de los hechos que llegaban hasta ellos funcionaba la oficina de propaganda.

Es obvio que el impulso, la voluntad de actuar, se expresa a sí misma en modos característicos diversos en diferentes tipos de sociedad; así, son diferentes la multitud, la banda, el partido político, o la secta. De hecho, puede expresarse en todas estas formas diversas, como fases sucesivas de evolución de una acción colectiva. Este impulso colectivo asume en el curso de esta evolución la mayoría de las características de una mente, es decir, de una mente colectiva. Así, Mary Austin habla de "mentalidad de rebaño". Le Bon describe la idiosincrasia de la "mente de la masa". Todos conocemos la expresión "mente de todos". La cuestión de dónde tal mente o voluntad está localizada, o si es una fase o un aspecto, como la conciencia de clase, de la consciencia individual, o si tiene algún tipo de existencia independiente, parece perder mucha de su importancia si cuando decimos "mente colectiva" nos referimos solamente a la unidad e íntima interdependencia que hace posible para los individuos actuar concertada y consistentemente. La capacidad de actuar colectivamente se crea, al parecer, por esa interpenetración de la mente que la comunicación implica.

En la banda o en otro grupo cerrado, en la que la asociación se basa en relaciones familiares o personales, la moral toda la forma de un esprit de corps (espíritu de grupo). En un partido político, que es un grupo en conflicto o en discusión se representa con una política, respaldada por un principio formal de algún tipo. En una secta religiosa la moral la sostiene la autoridad de un credo o los dogmas que son incuestionables. Parece que el partido nazi, en el curso de su historia, ha pasado por todas estas fases representadas por los tipos de agrupación que he mencionado. Su primera aparición fue en un putsch o golpe de estado llevado a cabo por un grupo tan mal organizado casi como una banda. A partir de ahí fue adquiriendo poder mediante una especie de guerra de bandas con los comunistas. Después se convirtió en un partido político y así se ganó un nuevo estatus cuando consiguió que partidarios suyos tuvieran representación en el parlamento alemán. Mientras tanto había tomado el carácter, al menos para sus líderes, de una secta fanática política, si no religiosa. Ahora mismo incluye entre sus posesiones espirituales no solamente un ritual y un credo sino, con el texto Mein Kampf, una Biblia. Finalmente, tienen en Hitler a su profeta, si no a su dios. Como secta política ha intentado suprimir toda forma de disensión, con todo el fervor y el vigor fanático de una nueva religión. Bajo su dirección, los alemanes están ahora comprometidos en una guerra santa para reorganizar la vida social del planeta en todos sus aspectos fundamentales, económico, social, político y religioso.

Si esta descripción es demasiado sumaria como para hacer justicia a los hechos históricos, al menos nos sugiere lo que la moral puede llegar a ser bajo un gobierno totalitario como el actual en Alemania, y lo que nunca será en una sociedad más secular como es la nuestra. 


\section{NOTICIAS}

La diferencia entre actividad y acción, según yo la concibo, está en que la acción tiene perspectiva, tiene un comienzo y un final, y en el proceso de transición del primer impulso en el que se origina hasta su consumación final, en un acto final abierto, es posible que se tope con sucesos que hagan precaria dicha consumación. La acción, en dos palabras, es la actividad controlada y dirigida. Esta es la razón por la que si la acción es prolongada y difícil, requiere, para asegurar el éxito, "voluntad" del individuo y, en el grupo, ánimo moral. Estas acciones y sus perspectivas nos dan las dimensiones del mundo en el que, podemos decir, la vida realmente discurre, a diferencia del mundo académico en el que lo que discurre no es la vida sino el pensamiento, que es una preparación para la acción.

Cada uno de nosotros vive en un mundo en el que constituimos el centro de todo, y las dimensiones de dicho mundo se definen por la dirección y las distancias desde las cuales llegan las noticias. Pues las noticias no son simplemente cosas nuevas, sino cosas nuevas de importancia; y llegan a nosotros con una urgencia que reclama nuestra acción, incluso si ésta radica simplemente en un cambio de actitud o en la reafirmación de una opinión.

Todo esto no tiene importancia excepto en tanto surgiere la relatividad de los mundos en los que los hombres viven activamente, y de cuya existencia cotidiana son de algún modo personalmente responsables. Lo que llega hasta nosotros en forma de un conjunto de acontecimientos ocurridos en otra parte, es decir, fuera o en los límites exteriores de nuestro mundo, es principalmente mito, leyenda o literatura: algo que quizás sea intrínsecamente interesante, pero no tan apremiante e importante que necesite que hagamos algo por su causa. Dado que el mundo se constituye de esta manera, descubrimos cómo se expande visiblemente en torno a nosotros, cuando la perspectiva de nuestros intereses prácticos y acciones se extiende.

¡Cuán profundamente han cambiado esas perspectivas en el proceso de la guerra actual!. De repente, tras la invasión de Francia, parece como si el planeta se hubiera hecho más pequeño y nuestro mundo más grande. Los aislacionistas son las personas que entre nosotros, por diversas razones que no articulan completamente, sospecho, no quieren o no pueden aceptar este cambio. Es en el dominio definido por la circulación de las noticias, y no precisamente por el mundo con el que tenemos contacto inmediato, donde se llevan a cabo nuestras grandes empresas colectivas: la guerra, la revolución, y el gobierno de la nación.

El trabajo de organizar, dar energía, y por encima de todo, de animar con una voluntad colectiva y un objetivo común a vastos ejércitos y a todo un pueblo es increíblemente complicado, pero con los modernos medios de comunicación no es un trabajo imposible. Sin duda que el gobierno alemán, con la ayuda de la censura y de la oficina de propaganda, parece haberlo conseguido en todo lo humanamente posible, y ha sido, capaz durante largos períodos, de imbuir a sus ejércitos y, en menor medida, a su población civil, de la unanimidad típica de la multitud psicológica estudiada por Le Bon. Esto ha ayudado a mantener la moral de la nación en las crisis sucesivas que han atravesado. 
El ejército alemán, según se oye, se ha democratizado mucho en el curso de su rejuvenecimiento. Ha surgido una camaradería entre los oficiales y los soldados que no se daba en el ejército prusiano antes de la revolución nacional-socialista. Esto ha creado en el ejército, y particularmente en la armada, un esprit de corps que no existía en la Primera Guerra Mundial.

Los técnicos políticos alemanes, con la ayuda de los académicos alemanes en diversas ciencias como las sociales, la historia, la antropología, y la nueva ciencia alemana, la Geopolitik, han desarrollado, como contribución a la moral nacional, una filosofía política que tiene como finalidad justificar la aspiración del pueblo alemán a la posición de raza dominante en Europa. Al mismo tiempo, han formulado un programa político que promete, si triunfa, culminar esa aspiración. Como Europa ha tenido y quizás aún tiene una posición dominante en el mundo moderno, la dominación alemana de Europa implicaría la dominación del mundo.

Finalmente, Herr Hitler y sus socios parecen haber inspirado en el ejército, si no en el pueblo, una fe invencible en su misión y su destino - una fe como la que se daría solamente en una secta religiosa. Hitler y su séquito refuerzan esa fe mediante el ritual, el mito, y sobre todo, mediante ceremonias que reviven de vez en cuando la atmósfera y la emoción exaltada con las que se concibieron originalmente. Esta fe en su misión y su destino se ha transmitido a los alemanes residentes en el extranjero, que viven en lo que podría describirse como la diáspora del último de los "pueblos elegidos". De esta fuente, otros pueblos, que de acuerdo con las doctrinas nazis jamás aspirarían a identificarse con la raza dominadora, se han visto igualmente infectados por su doctrina.

La moral y la disciplina, como Hermann Rauschning, autor de Revolution of Nihilism, afirma, son hoy una religión en Alemania y han conseguido en dicha nación un nivel altísimo de intensidad y efectividad. Se ha creado sin embargo mediante los mismos medios de solidaridad social y de disciplina que se crean allá donde las personas se asocian para formar sociedades y actuar colectivamente.

Una nación engloba en su amplio radio todas las formas comunes de asociación que conocemos, por ejemplo, locales, familiares, económicas, políticas, religiosas y raciales. La moral social debe solventar la cuestión de coordinar dichos grupos de manera que cooperen y no entren en conflicto. En el lenguaje de los técnicos políticos del partido nazi, se trata de la cuestión de la Gleichhaltung (circuito de identidad). Se ha conseguido subordinando, y finalmente fundiendo toda lealtad local y minoritaria en una lealtad totalitaria al estado nacional. Donde no se ha llegado a esa fusión, como en el caso de los alemanes luteranos y los católicos, al menos se ha intentado. Hay ya considerable literatura, psicológica y pedagógica, que muestra lo que se ha intentado y conseguido en el ejército, las escuelas y la prensa. ${ }^{11}$

La relación de las noticias con el ánimo moral no es tan obvia como la que existe con esa otra página del periódico, la editorial. Las noticias que recibimos y el periódico que leemos proviene de todas esas partes del mundo en las que nosotros y los otros lectores estamos interesados. Así es habitualmente, si el periódico no se

11 Vid. Guerra Psicológica Alemana: Encuestas y Bibliografía (New York: Comittee for National Morale, 1940). 
modifica de manera que nuestro interés en él sea más simbólico o literario, y no factual, y por tanto, con piezas o temas desconectados. Los periodistas han descubierto que, si otros elementos no cambian, las noticias se leen en ratio inversa a su longitud. Los periódicos nacionales semanales como Time y Newsweek han descubierto que pueden insuflar mayor interés noticioso a los temas 1) clasificándolos y 2) profundizando en los así llamados materiales de fondo, que nos permiten verlos en relación con otros sucesos ampliamente dispersos en tiempo y espacio. Poner una noticia en el contexto de una serie de hechos históricos o conectados de algún modo, les da un carácter que resulta histórico en algunos casos y en otros sociológico. Temas así tratados se convierten en historia en tanto encajen con la secuencia histórica. Se convierten en sociológicos si cuando se clasifican, arrojan luz sobre los procesos sociales independientemente del espacio o del tiempo en el que el proceso tiene lugar.

Según lo que venimos diciendo, las noticias no tienen influencia en la acción política o en la moral. Su influencia es más bien dispersar o distraer la atención y con ello hacer decrecer, más que crecer, la tensión. La función ordinaria de las noticias es mantener a individuos y sociedades orientadas y en contacto con su mundo y con la realidad, mediante ajustes pequeños. Normalmente su función no es iniciar movimientos sociales seculares que, cuando se producen con demasiada rapidez, producen consecuencias catastróficas. Por otra parte, cuando ocurre algún acontecimiento importante o perturbador, que "copa la primera página" y captura los titulares, continuará así durante días y semanas, como ocurrió con el secuestro del bebé Lindberg, que ocupó, con el subsiguiente juicio y ejecución de presunto secuestrador, las páginas de la prensa.

El asunto de dicho suceso o series de sucesos no son propiamente una noticia sino una "historia", un relato continuado, de hecho; y puede que vaya creciendo en interés y absorba más a los lectores conforme cada publicación en la prensa descubra algún nuevo desarrollo del mismo. De esta manera puede llegar a ser tan absorbente que merme el interés en historias menos llamativas, más corrientes, o locales. Cuando un relato noticioso va volviéndose más atrayente es porque se va publicando en fases que permiten a los lectores reflexionar, especular, o darle vueltas al significado de cada nuevo paso. En esas circunstancias los lectores de noticias interpretan los sucesos y todos los detalles en términos de sus propios recuerdos sobre experiencias propias o episodios conocidos similarmente trágicos. De este modo las noticias dejan de ser simples noticias y adquieren la significación de la literatura, pero de la literatura realista, de las "historias reales" de las revistas populares o de los relatos de los buhoneros ${ }^{12}$ que las antecedieron en la historia de los periódicos. Lo que fija y mantiene el interés del lector tiende a desorientarle, a poseerle.

Lo mismo ocurre en las guerras en las que nos parece asistir a la historia en directo; las guerras en las que están implicados los destinos de naciones o civilizaciones. Cuando la atención se concentra en esos acontecimientos que no son simples

12 Hughes, Helen, The Human Interest Story (Chicago, Univ. of Chicago Press, 1940). 
temas sino capítulos de la historia actual, nosotros, que somos sus espectadores, nos implicamos empáticamente en ellos. En esas circunstancias es inevitable que interpretemos los acontecimientos y la historia de manera diferente según nuestras diferencias en experiencias personales y según nuestros prejuicios. Es inevitable que tomemos partido, dado que la discusión tenderá a resaltar y a hacer surgir las diferencias así como a oscurecer los puntos de vista fundamentales en los que estamos unidos, al menos temporalmente. Esto resulta una desgracia, quizá, pues la moral nacional requiere por encima de todo que en una crisis se actúe como una nación, y se esté unido como pueblo.

La opinión pública no es, por tanto, un buen indicio de la moral del país porque, como es fruto de la discusión, intensifica las diferencias. La opinión pública está en la superficie de las cosas, y no refleja las actitudes y puntos de vista en los que la comunidad se mantiene unida. La misma existencia de la opinión pública es evidencia en sí misma de que en el país no hay, en un momento dado, unanimidad respecto a lo que como país o como nación se debería hacer. Sin embargo, cuando las cosas se discuten y finalmente quedan ya fuera de discusión, la dirección que la opinión pública asume en el curso del tiempo nos indica la que la voluntad colectiva, en su proceso de formación, ha tomado. Esto es lo que muestran las encuestas de Gallup.

La discusión pública de la política pública durante los períodos de crisis, cuando tiende a agriarse, invariablemente trae a la superficie no solamente puntos de vista discrepantes sino los recuerdos y experiencias originales sobre las que dichas interpretaciones de los hechos se basan. No hay más que leer las opiniones exasperadas y a menudo ultrajantes que se expresan en las Cartas al director para reconocer cómo son reflejo de frustraciones personales y de experiencias emocionales profundas cuya fuente a menudo es tan oscura que requerirían la técnica de un psicoanalista para sacarla a la luz. Pero en tanto la libertad de discusión nos lleva a la fuente de esa violencia emocional y por tanto la saca a la luz, la discusión de dichas controversias en cierta medida contribuye indirectamente a la moral nacional. Esas cartas controvertidas sirven de purga para las mentes de aquellos que las escriben, y dan consuelo a aquellos que las hubieran escrito en caso de haber podido

En un número reciente del Detroit Free Press di con un artículo muy inteligente y nada mal intencionado de Harold Ickes. Este autor escribe cartas al editor exasperantes y exasperadas. Bien, probablemente sea cierto, pero para mí supuso un gran consuelo leerlo, igual que lo fue seguramente para otros. Exagera, sin duda, como un hombre exasperado lo hace; pero también afirma cosas que todos pensamos y estoy seguro, por mi propia experiencia, de que su escritura sube la moral del país. Recuerdo lo que se decía de Lindbergh, a quien admiro. Me gustaría oírle al respecto del Senador Gerald Nye. Seguramente ya ha opinado sobre este senador de Dakota del Norte, pero si ha sido así me lo he perdido.

Sacar todas esas cosas del pecho es, como he sugerido, bueno para el país. Mejora la moral y además de eso, podemos estar seguros de que nadie con la amargura de dichos escritores se convertirá en un quintacolumnista. Esas cartas al director no son opinión pública, empero. Son simplemente opiniones personales. Si se las acompaña con una confesión "completa, repentina, y amarga", que revela el contex- 
to en el que se formaron, arrojarán mucha claridad sobre las fuentes del descontento que hacen difícil, en un país como el nuestro, compuesto de gente que ha venido de todos los rincones de la tierra, unirse completamente a corazón abierto, excepto en las situaciones de grave emergencia nacional, en una política absolutamente totalitaria, como la que requieren dichas graves emergencias nacionales.

Dije al comienzo de este artículo que la guerra tendía a asumir el carácter de un proceso dialéctico en el que las ideas, y no la fuerza, asumen el papel principal. Cuando los acontecimientos hacen a los objetivos y asuntos según se concibieron y establecieron originariamente obsoletos, las partes beligerantes hallan necesario de vez en cuando redefinir sus objetivos y descubrir bases más fundamentales y más razonables para justificar el camino que han elegido seguir. A largo plazo, particularmente si el conflicto se prolonga, se hace necesario no solamente responder a las preguntas que la reflexión genera en el país, sino justificar los objetivos y las conductas de la guerra ante el público exterior que no está implicado completamente en un bando o en otro. En este caso la guerra deja de tener el carácter de un coup d'état internacional, que pretende mediante una Blitzkrieg (guerra instantánea) producir un estado mundial sin más, y se va convirtiendo más y más en una guerra de ideas y de ideologías. Estas guerras inevitablemente llegan a tener el carácter de revoluciones. Terminan por generar no simples cambios en las posesiones materiales, sino en las instituciones y en las concepciones fundamentales de la vida. Es, de hecho, la razón por la que si lleva a cabo esta tarea las guerras tienen una función en el proceso histórico.

En esas circunstancias, la moral soportada por un principio de razón deja de ser un asunto de esperanza o de temor y se convierte en una fuerza moral. A la larga esa fuerza moral es la que alcanzará los objetivos por los que se emprendieron las guerras.

\section{RESUMEN}

Este texto legendario muestra la primera teoría de la acción social fundamentada en las noticias, generando la base académica para desarrollar una teoría de la función ética y democrática de las noticias.

Palabras clave: Robert Ezra Park, moral, noticias, periodismo, acción social.

\section{ABSTRACT}

This legendary text shows one of the first theories of social action and the news, founding the academical basis to develop an ethical and democratical idea of the function of journalism.

Keywords: Robert Ezra Park, morale, news, journalism, social action.

\section{RÉSUMÉ}

Ce texte légendaire nous montre la première théorie de l'action social fondée dans les nouvelles, en aportant la base académique pour le devéloppement d'une théorie de la fonction étique et democratique des nouvelles.

Mots clé: Robert Ezra Park, morale, nouvelles, journalisme, action sociale. 